\title{
4D micro-scale, phase-contrast $X$-ray imaging and computed tomography of HMX-based polymer-bonded explosives during thermal runaway
}

DOI:

10.1016/j.combustflame.2020.12.025

\section{Document Version}

Accepted author manuscript

Link to publication record in Manchester Research Explorer

Citation for published version (APA):

Parker, G., Eastwood, D., Storm, M., Vitharana, K., Heatwole, E. M., Lopez-Pulliam, I., Broilo, R. M., Dickson, P. M., Martinez, A., Rau, C., \& Bourne, N. K. (2021). 4D micro-scale, phase-contrast X-ray imaging and computed tomography of HMX-based polymer-bonded explosives during thermal runaway. Combustion and Flame, 226, 478489. https://doi.org/10.1016/j.combustflame.2020.12.025

\section{Published in:}

Combustion and Flame

\section{Citing this paper}

Please note that where the full-text provided on Manchester Research Explorer is the Author Accepted Manuscript or Proof version this may differ from the final Published version. If citing, it is advised that you check and use the publisher's definitive version.

\section{General rights}

Copyright and moral rights for the publications made accessible in the Research Explorer are retained by the authors and/or other copyright owners and it is a condition of accessing publications that users recognise and abide by the legal requirements associated with these rights.

\section{Takedown policy}

If you believe that this document breaches copyright please refer to the University of Manchester's Takedown Procedures [http://man.ac.uk/04Y6Bo] or contact uml.scholarlycommunications@manchester.ac.uk providing relevant details, so we can investigate your claim.

\section{OPEN ACCESS}




\section{D micro-scale, phase-contrast X-ray imaging and computed tomography of HMX-based polymer-bonded explosives during thermal runaway}

G.R. Parker ${ }^{\mathrm{a}, *}$, D.S. Eastwood ${ }^{\mathrm{b}}$, M. Storm ${ }^{\mathrm{c}}$, K. Vitharana ${ }^{\mathrm{b}}$, E.M. Heatwole ${ }^{\mathrm{a}}$, I. Lopez-Pulliam ${ }^{\mathrm{a}}$, R.M. Broilo ${ }^{\mathrm{a}}$, P.M. Dickson ${ }^{\mathrm{a}}$, A. Martinez ${ }^{\mathrm{d}}$, C. Rau ${ }^{\mathrm{c}}$, N.K. Bourne ${ }^{\mathrm{b}}$

a) Los Alamos National Laboratory, PO Box 1663, MS P917, Los Alamos, NM 87545, USA

b) University of Manchester, Diamond Light Source, Harwell Campus, Didcot OX11 ODE, UK

c) Diamond Light Source, Harwell Campus, Didcot OX11 0DE, UK

d) Health and Safety Laboratory, Harpur Hill, Buxton SK17 9JN, UK

\section{Abstract}

High-resolution synchrotron $\mathrm{x}$-ray radiography with computed tomography is used to observe the evolution of porosity created by thermal exposure in two HMX-based polymer-bonded explosive compositions; LX-04 and BX-63. The measurements were made in situ, over an extended period of time, during which the samples were heated on a slow-rate thermal trajectory. The tests ended with thermal-runaway to ignition after which the samples were consumed by combustion. The primary means of damage appears to be from mechanical debonding of the HMX-binder interface with secondary contribution from chemical decomposition. Confinement and binder properties affect the amount of porosity and permeability that develops. Additionally, observations were made describing the emergence and structure of an internal ignition volume, the formation and transport of a preignition melt layer, and how the early stages of combustion were affected by material morphology, mechanical confinement and melt. The contact angle between molten HMX and the fluoropolymer, Viton A, is also presented. For the first time we have time-resolved x-ray images of ignition in sufficient detail to verify the mechanism of cookoff in polymer-bonded explosive compositions.

\section{Introduction}

Public safety is a key concern during transportation of energetic materials, including propellants and high explosives (HE), particularly in systems where casements contain HE and confine combustion. Specifically, regulatory agencies are interested in the scenario of an energetic material being exposed to fire, which historically has been the cause of numerous violent explosions during transport on land and at sea $[1,2]$. The response to thermal exposure of a class of HEs called polymer-bonded explosives (PBXs) is a particularly challenging problem. PBXs are composite materials in which explosive crystals are encapsulated within compliant polymer binder systems and pressed to high bulk density. The composite nature of these materials requires understanding the thermal response of each component, as well as how they interact chemically and physically. The potentially fatal consequences and costs of explosives transportation accidents have incentivized research laboratories and university groups in many nations to study the response of such materials to thermal insult. The 
ultimate goal is to be able to numerically model and thus predict the response of the explosive charge when subject to thermal and mechanical abuse. Due to the heterogeneous nature of PBXs, mesoscale characterization of material microstructures is pivotal to the success of contemporary modeling efforts [3-5].

Slow application of heat from an external source to an explosive charge can eventually begin solidstate exothermic decomposition reactions that, in turn, generate sufficient internal heat to commence a self-sustaining process of thermal-runaway- to-ignition (aka slow cookoff). When the heat production rate from reactions inside the bulk exceeds the thermal loss rate at the external boundary, exacerbated by the generally poor thermal conductivity of the PBX, the hottest location will migrate from the surface inwards. Positive feedback between decomposition reaction rates, which are exponentially dependent on temperature and heat production from reaction, leads to enhanced localization creating a hotspot that will ultimately attain the ignition temperature. With the right conditions, the process of self-heating can sustain itself, even after the external heat source is removed, hence the process of slow cookoff is sometimes described as thermal auto-ignition.

In addition to heat, thermal decomposition of the condensed matter generates reactive gaseous products, and concomitantly, porosity. Also, differential thermal expansion between components and casings can cause internal stresses, producing fracture or debonding. With sustained thermal exposure, porosity can grow and connect into a flow network through which product gases can travel redistributing reactive potential and heat throughout the bulk. If the pore network accesses a free surface, gases will escape along with thermal energy. Consequently, gas permeation in connected pore networks can affect the time to, location of, and volumetric extent of ignition during such cookoff events. Following ignition, porosity permits flame intrusion into the bulk (i.e., forced convection of hot, combustion-product gases) [6] and also provides space for compaction of the porous medium under explosively driven loading. Porosity sensitizes HE, to a high degree, via a shock compression mechanism for hotspot formation causing explosion and/or detonation [7,8]. Altogether, porosity is key to many of the physical processes involved in the critical response known as the deflagration-todetonation transition (DDT) [9]. As a result, characterization of porosity due to thermal damage of HE has been an active area of research in the explosives community since the last century [10-20].

\section{Background}

\subsection{Ex situ characterization methods}

Researchers have previously performed reflected polarized light microscopy $[10,11,21,22]$, scanning electron microscopy [12], and x-ray computed tomography (CT) [13] to characterize porosity in thermally damaged PBX targets. These techniques, sometimes combined with digital image analysis, were useful for describing the qualities of the pore field, as well as quantifying the extent, feature size and spatial distribution of voids $[10,11]$. However, these techniques require measurements to be made ex situ and error arises since the morphology changes upon cooling. Typically, 2D imaging techniques, most often surfaces examined within sectioned samples, require assumptions (e.g. the observed structures are isotropic) to usefully apply stereological methods for extrapolation of 2D measurements into estimations of quantities describing the actual three dimensional microstructure. Often these assumptions do not apply as the nature of the damage is not isotropic, especially when mechanical confinement exists [14]. Metal casings, enclosing explosive components, not only affect thermal transfer, but can also mechanically inhibit expansion. Inhibition of expansion is especially pronounced in $\mathrm{HMX}^{1}$-based PBXs which experience significant growth when

\footnotetext{
${ }^{1} \mathrm{HMX}$ (octahydro-1,3,5,7-tetranitro-1,3,5,7-tetrazocine) is a crystalline high explosive material.
} 
HMX crystallites in the composite transition between the $\beta$ and $\delta$ polymorphs in the temperature range $158-175{ }^{\circ} \mathrm{C}$ [23]. Inhibition of expansion of HMX-based PBXs against relatively strong confinement can cause internal stresses that may inhibit the phase transition, or reduce/crush-out porosity. With HE cylinders in radially confining sleeves (i.e. tube confinement), the samples can only expand in the orientation of the cylindrical axis, thus cracks form and open only in that direction [14]. This effect was previously noted by comparing microscopy in PBX samples that were damaged inside a confining sleeve with samples that were damaged unconfined; the samples damaged in confinement had an anisotropic pore field distribution with overall lower porosity [11].

\subsection{In situ characterization methods}

Small-angle neutron scattering has been used post-mortem and in situ to measure the size distribution of porosity, but this technique does not provide information describing the structure or interconnectedness of porosity $[13,18,19]$. Finally, in situ measurements of specific permeability (an effect of porosity) in thermally degrading PBXs were also made [15-17,20], both within a confining sleeve and unconfined. The samples damaged in confinement showed reduced permeability, in the flow direction of the cylindrical axis, when compared to the unconfined samples. Whilst informative, these in situ methods, by themselves, lack the capability to geometrically characterize or directly quantify the porosity.

\subsection{Dynamic measurements}

The pioneering work by Smilowitz and Henson, using dynamic x-ray [24] and proton radiography [25], revealed many important features that evolve prior to, and during, thermal auto-ignition of solid explosives. They observed, in a variety of metal-cased PBXs, the formation and growth of an internal lower density cavity prior to onset of ignition. This region was interpreted to be at the location of the most advanced thermal decomposition of the solid phase. Inside this ignition volume, gaseous decomposition products recombine exothermically and initiate combustion [26,27]. Following ignition, they observed rapid propagation of reaction (inferred by loss of density in the radiographs), that they assigned a convective burn mode. This mode of burn propagation relies on transfer of heat from hot product gases infiltrating into voids and cracks ahead of the ignition front [28]. The convective propagation mode, or lack thereof in some materials, has been shown by other researchers to be strongly dependent on the thermal stability and mass fraction of the polymer binder systems used in different PBX compositions [29].

In all cases, there has been a trade-off between what was practical using existing measurement techniques and what could be quantitatively deduced. This has left uncertainty in the ability to resolve the micromechanisms that lead to decomposition and has limited the models that have been derived.

However, the advent of modern $\mathrm{x}$-ray sources has opened a new experimental suite of tools. By these means it is possible to make in situ, 3D, dynamic measurements of thermal damage evolution with micrometer resolution and a mesoscale field of view. Further, both slow decomposition routes (on the order of many hours) and fast (on the order of seconds or less) can be studied as reactive materials degrade, and this, for the first time, allows us to unequivocally match mechanistic routes relative to the post-mortem measurements of the past. In this paper, we present findings that build upon this work with the benefit of providing well-described and precisely quantified conditions (in terms of morphology) prior to ignition, gained from micrometer resolution, in situ CT. We also present higher resolution, 2D dynamic radiographs of the thermal runaway to ignition that provide unprecedented detail inside and around the internal ignition volume, including insights into the initiation and propagation of combustion. 


\section{Experimental methods}

This work was performed at the Diamond Light Source I13-2 imaging branch, built in collaboration with the University of Manchester. Beamline I13-2 provides an intense broad spectrum 'pink' x-ray beam over 18-32 keV, with a weighted mean spectral energy of $27 \mathrm{keV}$, ideal for in-line phase contrast imaging and tomographic reconstruction [30]. After passing through the sample, the x-rays illuminate a $500 \mu \mathrm{m}$ LuAG:Ce scintillator, which is imaged by a PCO Edge 5.5 camera. The lowenergy, but high brilliance, of the beam, is useful for lower density materials, like PBXs, where x-ray absorption contrast is weak [31]. The high photon flux allows short, image-sensor integration time which minimizes motion blurring when sequentially capturing the evolving porosity in 3 spatial dimensions over an extended period of time. The field of view $(2.1 \times 1.8 \mathrm{~mm})$ at the highest resolution $\left(0.81 \mu \mathrm{m} \mathrm{px}^{-1}\right)$ allow us to image a statistically representative volume of an ensemble of microstructures while also observing mesoscale physical phenomena at lower resolution $\left(2.6 \mu \mathrm{m} \mathrm{px}^{-1}\right)$ with a larger field of view $(6.7 \times 5.6 \mathrm{~mm})$. Figure 1 shows typical image quality with discrimination between crystal, binder and void fraction clearly possible.

\subsection{Thermal exposure experiments}

To heat the PBX samples, a furnace was designed to integrate with existing beamline hardware at the facility (Fig. 2). The system gave precise temperature control, provided beamline protection in the event of explosive reaction, and had x-ray transparent aluminum windows for imaging.

Test specimens were held by a section of thin-walled $(100-175 \mu \mathrm{m})$ aluminum tubing, attached to the facility's rotation stage. Samples were pressed cylinders ( $6 \mathrm{~mm}$ long $\times 4 \mathrm{~mm}$ diameter). For the unconfined configuration, the sample cylinders were inserted $\approx 1 \mathrm{~mm}$ into the end of the $\mathrm{Al}$ tube and measurements were made above the inserted portion. The confined samples were inserted completely inside the $\mathrm{Al}$ tube with RTV silicone plugs at both ends. Two non-contact thermocouples, one above and below, measured the local thermal environment. The samples were heated at the maximum rate from room temperature to above $100{ }^{\circ} \mathrm{C}$ and at a constant heating rate $\left(1.5{ }^{\circ} \mathrm{C} \mathrm{min}-1\right)$ thereafter, until thermal runaway and auto-ignition. Total duration ranged $\approx 3-5 \mathrm{ks}$.

From earlier research, we hypothesized that two factors were likely to dominate the generation of porosity during thermal exposure: thermal decomposition and mechanical confinement. To examine the effect of confinement we simply controlled for thermal decomposition by testing the same PBX material in either a confined or unconfined configuration. To test the effect of thermal decomposition we controlled the confinement variable (i.e. we tested unconfined) and varied the PBX composition. As model PBX materials for this study, we chose the HMX-based explosives BX-63 and LX-04 for their similar mass-percent solids loading, but with vastly different binder types. The PBX composition details can be found in Table 1. Difference in response of these materials would be predominately due to the thermo-chemcial and -mechanical response of the binder component because both PBXs have similar HMX mass fractions. Specifically, we expected BX-63 with binder that contains nitrocellulose, known to start decomposing and releasing gas around $177{ }^{\circ} \mathrm{C}$, to develop more porosity than LX-04 with its more thermally stable Viton A binder. In fact, thermogravimetric analysis shows a 4-5\% weight loss, along with an exothermic event, in the range of $170-200 \circ \mathrm{C}$. This is likely due to the thermolysis of the nitrate ester linkage, with corresponding release of NO2 gas. All factors considered, the amount of porosity generated was hypothesized to rank as follows: BX-63, unconfined $>$ LX- 04, unconfined $\geq$ BX-63, confined. 
In a period in which chemical decomposition rates were relatively low, during heating, and well before auto-ignition, tomographic sequences (consisting of 1800 projections) were taken as the sample was rotated $180^{\circ}$ around the cylindrical axis. Scan sequence duration and interval were $18 \mathrm{~s}$ and $360 \mathrm{~s}$, respectively. The projections were normalized to the illumination 'flat field' before tomographic reconstruction using a filtered back projection algorithm in the Savu package [32]. Voxel-level image analysis of a sub-sample of the 3D reconstruction was completed for quantitative and qualitative characterization of the pore-field extent and nature.

\subsection{Image analysis}

Image analysis was performed with the Avizo software package (ThermoFisher Scientific) on a $2 \times 2$ $\times 2 \mathrm{~mm}$ sub-volume. Gaussian filtering was used to remove background noise. The filtering reduced the effective resolution so that the smallest feature (i.e. pore or crystallite) that could be analyzed was $3.2 \mu \mathrm{m}$, with the consequence being that distinguishable features smaller than this limit were counted in the 3-4 $\mu \mathrm{m}$ bin. After filtering was applied, the pores were segmented from the background using binary thresholding calibrated by the user to match the known value for initial porosity, $\varphi_{\mathrm{i}}$, which was calculated by the following equation:

$$
\varphi_{i}=\frac{\left(\rho_{t}-\rho_{i}\right)}{\rho_{t}},
$$

where $\rho_{\mathrm{t}}$ is theoretical maximum density (TMD) and $\rho \mathrm{i}$ is the initial geometric density of the PBX part calculated from measurements of weight divided by size. Once the pores were segmented, the pore volume fraction (porosity, $\varphi$ ) was calculated by dividing the total pore volume by the volume that was analyzed. The analysis methodology relies on user adjustment to select a binary thresholding value that accurately discriminates pore-volume from non-pore-volume. The threshold value was calibrated iteratively to fall within an acceptance criterion of $\leq 0.011$ on the difference between the geometric $\varphi_{i}$ and the image analysis result of the initial image. This difference was propagated as systematic uncertainty, which combined with measurement uncertainty from effective imaging resolution, produced the total uncertainty captured by the error bars in the figures. Additional analysis was done by separating individual pore bodies via the Separate Objects algorithm. Following this step, volume and diameter were measured by the software for each pore body in the sample population, so that statistical analysis could be performed.

\subsection{Radiography}

Immediately before the time-of-ignition, decomposition rates increased such that the 18-second scanduration was too great to eliminate motion blur and CT reconstruction became error prone or impossible. At this time we switched to a $1.25 \times$ objective (resolution: $2.6 \mu \mathrm{m} \mathrm{px}^{-1}$ ) and captured $2 \mathrm{D}$ projections at a frequency of $55.56 \mathrm{~Hz}$ with $10 \mathrm{~ms}$ exposures. Images were captured in this mode of operation during the ignition event and subsequent combustion.

\subsection{Contact angle measurements}

A small oven was constructed to heat single HMX crystals through their melt and decomposition to gas (Fig. 3). The oven consisted of an aluminum reflector, with holes for optical access and illumination, enclosed on the bottom with a glass microscope slide. A cartridge heater was wired to 
the top of the oven and was powered with a DC power supply. Video was recorded at 100 frames per second on a Miro camera (Vision Research, Inc.), triggered manually once melting began. A long range microscope lens was used to provide magnification.

The sample consisted of a 1-mm-thick, $15 \mathrm{~mm} \times 15 \mathrm{~mm}$ square sheet of Viton A rubber, bonded with high temperature epoxy to a flat steel plate for rigid support. The surface of the Viton A was cleaned with isopropyl alcohol prior to emplacement of an HMX crystallite.

Heat was applied until the crystal transitioned phases from solid to liquid to gas. As the HMX melted, it also began to boil producing bubbles that popped and sometimes expelled small droplets that landed nearby on the Viton A substrate; these droplets were generally well formed with good symmetry and were amenable to the sessile drop technique for contact angle measurement. The subset of droplets that landed within the focal depth of field of the lens were used for analysis. Care was taken to use images from the video sequence taken immediately after contact with the substrate to minimize error from further vaporization and droplet edge recession.

Images were imported in ImageJ software (U.S. National Institutes of Health) where the DropSnake plugin was applied to measure the static contact angle on both the left and right edges of each drop. A total of eighteen measurements were made on two well-formed droplets in sharp focus. Mean angle and standard deviation were calculated.

\section{Results and discussion}

\subsection{Porosity evolution}

Figures 4 and 5 show the temperature and exposure duration effects on the development of porosity, as well as the final CT images, for samples of BX-63 and LX-04, respectively, in the unconfined configuration. Figure 6 shows the same for BX-63 in the confined configuration. In all cases, porosity increases and is distributed in a spatially uniform manner, with the final porosity, $\varphi f$, being greatest in the unconfined samples. Refer to supplemental materials for animations of porosity evolution.

The normalized pore-diameter distribution (Fig. 7) reveals that $\varphi f$ for the confined sample contains a higher number of smaller pores per unit volume than the unconfined samples. Also, a bimodal size distribution develops in the unconfined samples, with the second mode comprising larger pores. The CT images are helpful to visualize the final damage state showing the different character of the porosity in each confinement configuration; most notably the unconfined samples exhibit a population of larger conjoined pore bodies interspersed amongst the smaller pores. Presumably these are the features comprising the second, larger, mode in the distribution. This fraction of the porosity is extragranular and its character suggests that it was primarily generated by mechanical debonding at the binder-HMX interface (Fig. 8 and supplemental materials for animation). These features are not present in the confined sample of BX-63, where mechanical constraint imposed by the confining sleeve prohibited separation. Following this reasoning, for samples damaged in confinement the porosity generated, $\Delta \varphi=\varphi \mathrm{f}-\varphi \mathrm{i}$, would arise only from chemical decom position as described in Section 3.1. In this work, for the BX-63 in confinement, $\Delta \varphi=0.018 \pm 0.025$. In contrast, for the unconfined BX-63 $\Delta \varphi=0.120 \pm 0.008$ and for the LX-04, with thermally stable binder, $\Delta \varphi=0.082 \pm$ 0.019 . With the greater $\Delta \varphi$ values for the samples that were unconfined during thermal exposure, we conclude that most of the porosity created is due to micro-mechanical dedonding, with a lesser, but not insignificant, contribution from thermal decomposition of binder components to gas.

Figure 9 shows the fraction of total porosity that is connected. Here we see that the connected pore fraction increases significantly as the unconfined samples are heated through the temperature range 
of $\approx 120-180 \circ \mathrm{C}$. Note that the heating rates were dif ferent between the unconfined BX-63 and LX04 through this temperature range (see Fig. 4a and 5a), with the LX-04 having been heated more rapidly. The higher rate would lead to greater thermal gradients within the sample from the outer surface inward and this greater disequilibrium would likely explain the apparent lag in the development of connected porosity in the inner region of the LX-04 sample. The heating rate artifact appears to resolve in the vicinity of $150{ }^{\circ} \mathrm{C}$ and above, where the LX-04 heating rate slows and eventually equals that of the $\mathrm{BX}-63$ at $\approx 180 \circ \mathrm{C}$, causing the thermal gradients to reduce and the difference in connected porosity fraction to diminish. These data also reveal that confinement has a strong effect on the fraction of porosity that becomes connected, with the confined BX-63 developing almost none.

\subsection{Ignition volume development in HMX-based PBXs}

Examination of the dynamic radiography (Fig. 10) taken during auto-ignition shows the development of an internal ignition volume for each test $\mathrm{HE}$ and confinement configuration.

Figure 10, (top) shows the cookoff response of BX-63 in the unconfined configuration. The development of an oblate-shaped, lower-density feature begins in the second frame and grows steadily thereafter; this is the ignition volume. The increase in $\mathrm{x}$ - ray transmission intensity in this feature is due to mass transport away from the ignition volume into the surrounding porous medium. This inference is strongly supported by the formation of a locally denser zone at the edge of the volume where mass is accumulating and density increasing. Initially, this denser zone, revealed by a decrease in transmission intensity, is approximately $500 \mu \mathrm{m}$ thick, but gets thinner as thermal runaway progresses and the ignition volume grows. We believe this feature is a pre-ignition melt layer and will discuss our reasoning and its significance in Sections 4.4 and 4.5.

Figure 10 (middle) shows the behavior of confined BX-63. Under these conditions, the ignition volume forms and grows, but does not develop a resolvable pre-ignition melt layer. This is inferred to be the result of lower permeability and less porosity.

Figure 10 (bottom) shows the behavior of unconfined LX-04. A relatively small ignition volume forms near the top of the cylinder and the internal pressure promptly forces an opening to the upper free surface by bulging and fracturing the PBX. Similar to the laterally confined sample, there is no evidence of a pre-ignition melt layer.

\subsection{Permeability}

It has been shown that thermally damaged PBXs develop permeability to laminar flow. Asay et al. [15] measured permeability of hot PBX 9501 in both unconfined and laterally confined conditions, similar to the confinement employed in this study. While PBX 9501 is a different composition $2^{2}$, it shares enough similarity with BX-63 to offer useful insights. From Asay et al. we learn that lateral confinement during heating caused $\approx 2.3 \times 10$ times less permeability by a mechanism whereby boundary confinement inhibited or reduced the expansion of the PBX and the opening of pores within. The same effect on porosity was observed in this study with BX-63. Similar permeability measurements were performed by Hsu et al. [33] with unconfined LX-04 showing it be $\approx 3.9 \times 10^{4}$ times less permeable than unconfined PBX 9501. This reduction was attributed to the thermal stability

\footnotetext{
${ }^{2}$ Both BX-63 and PBX 9501 are highly filled with HMX and both have binder systems that will decompose with thermal exposure.
} 
of the Viton A binder in LX-04 and a similar difference would therefore be expected when comparing LX-04 to BX-63.

Indeed, comparison between BX-63 and LX-04 show differences in the evolution of the ignition volume that most likely indicate the effect binder decomposition, or lack thereof, has on gas permeability and auto-ignition behavior. Similarly, a comparison between the unconfined and confined BX-63 reveals differences that can be attributed to the effect that confinement has on the permeability of the damaged PBX. The duration from emergence of the ignition volume to breakout at the top surface of the HE varied as a function of both the apparent permeability of the damaged PBXs and the proximity of the origin of the ignition volume to the top surface. Unconfined BX-63 took the most time $(\approx 11-12$ s) for breakout, while confined BX-63 took the least time $(\approx 3-4$ s). The unconfined LX-04 ranked in between at $\approx 6-7 \mathrm{~s}$. These values correlate with the ranking of $\varphi f$ for each sample, indicating there was relatively greater gas permeation in the higher porosity samples.

\subsection{Formation and transport of a melt layer}

We hypothesize four plausible mechanisms for the formation and outward migration of the denser layer surrounding the ignition volume in unconfined BX-63.

1. Compaction with local reduction in porosity.

2. Gas flow from the ignition volume into adjacent porosity convectively heating and melting pore walls, and/or condensing, to produce a stationary liquid phase.

3. Melt locus expanding from thermochemical runaway creating stationary liquid phase that displaces gas locally from porosity and increases unit cell (i.e., voxel) density.

4. Melt with transport of liquid into adjacent porosity (i.e., wicking).

As evaluated in Appendix A, pressure driven compaction that crushes porosity would be resolvable, but is an unlikely explanation because the dense layer continues to migrate without thickening after the ignition volume breaks out through the top surface and ignition-volume-pressure is relieved.

Before ignition volume breakout, gas flow effects in the surrounding explosive are likely, but would not explain the detection or persistence of the dense zone after breakout, when the driving pressure drops to ambient and gas flow into porosity from the ignition volume would cease. We also show in Appendix A that the density change from $\delta$-HMX to liquid HMX is approximately

$3.7 \%$ and that the volume fraction of gas displaced by melt of the HMX, without flow of the liquid, produces a density change (per unit cell) that is too small $(\approx 0.9 \%)$ to be detected by radiography. This reduces likelihood that the observed feature results from both the convective heating and the expanding melt locus mechanisms. We also show, however, that flow of liquid HMX by capillary action between adjacent, connected unit cells can produce a resolvable change in density (e.g., a unit cell with wetted porosity is $\approx 16.9 \%$ denser than a cell with unwetted porosity) with complete wetting of the connected pore space. Further, this transport mechanism would not depend on gas pressure to force flow, thus would persist after ignition volume breakout.

All considered, we conclude that the feature is a layer consisting predominately of molten HMX, or a mixture of molten $\mathrm{HMX}+$ binder $^{3}$, initially produced by convective heating from hot product gas infiltration. Once the liquid phase is created, capillary action becomes the dominant mechanism for

\footnotetext{
${ }^{3}$ The state of the binder is unknown at these temperatures $(\approx 250-290 \circ \mathrm{C})$. The initial volume fraction of binder is small, at $11 \%$, and, for reasons described in Section 3.1, some fraction of the binder will have decomposed to gas once temperature rose above $\approx 170 \circ \mathrm{C}$. So while the chemical composition of the molten phase is not precisely known, we believe it is likely to be predominately molten HMX.
} 
transport causing the liquid to infiltrate into pores - allowing radiographic detection - at a rate similar to the pre-ignition rate of regression of the surface of the ignition volume.

The pre-ignition melt layer, however, is not observed in the confined sample of BX-63, or the unconfined LX-04. The discrepancy with the confined BX-63 can be explained by the lesser amount of porosity, the smaller size distribution of the pores and, most importantly, by the observation that most of the existing porosity did not form a connected network (i.e., it has low permeability). The LX04, however, is more similar morphologically to unconfined BX-63 in terms of the quantity and connectedness of its porosity, though it is also less permeable than unconfined BX-63. In LX-04, it is likely that Viton A makes up a significant compositional fraction of the total surface area of the pores because: 1) most of the porosity appears to be formed from binder-HMX debonding; 2) Viton A comprises a $\approx 14.1 \%$ volume fraction of the PBX after heating and bulk damage; and 3 ) it is thermally stable at the HMX melt temperature. We propose the absence of wicking in LX-04 is due our observation that molten HMX is only partially wetting on Viton A, with a measured contact angle of $73.43 \pm 4.97$ (Fig. 11), and this would reduce or effectively eliminate capillary action through pores with Viton A surfaces. Without liquid flow from a donor cell to an acceptor, there would not be a resolvable change in unit cell density. We believe this modest, but not insignificant, surface energy effect combined with the fact that LX- 04 does not develop as many larger pore bodies (see Fig. 7), is adequate to explain the lack of an HMX wicking mechanism for this PBX composition.

It is important to differentiate this preignition occurrence of a melt layer from the typical description of a post-ignition melt layer that forms during normal conductive burning where heat is transferred to the condensed phase from the flame. As a result of lower thermal gradients from the ignition volume outward, and the proposed wicking of liquid outward, this layer is thicker than what would be found in a melt layer produced on the surface of a solid undergoing normal conductive burning, where the thermal gradient from the flame to fuel surface is greater. Indeed, following ignition, the observed melt layer in unconfined BX-63 rapidly becomes thinner, and for the LX-04 and confined BX-63, a thin melt layer only becomes visible after ignition. The implications for transport of a melt layer are important for understanding post-ignition response, as it is sometimes assumed that convective heat transfer from hot gas infiltration is responsible for enhancing propagation rates of an ignition front through thermally damaged PBXs. A melt layer that occupies porosity could possibly inhibit a gas-mediated convective propagation mechanism by locally reducing permeability. Instead, it is reasonable to expect that heat would be transferred from the flowing liquid to newly contacted pore surfaces analogously to gas-mediated convective heat transfer. Hence, this transport phenomenon could be described as a liquid-mediated convective propagation mechanism. To fully describe the nature of the hypothesized mechanism of liquid transport by capillary action, future studies with higher magnification radiography will be required in order to resolve the micro-scale details of the melt zone.

\subsection{Ignition and burn progression}

Refer to Fig. 13 for the following discussion. The rate of growth of the ignition volume, measured by regression of the higher density surrounding material, is initially slow, but switches suddenly to a higher rate following breakout. At this time, the pressure inside the ignition volume is relieved (in the case of the confined sample the rate increase comes after the silicone plug is forced out of the end of the tube) and the rate of surface regression increases in each trial (for the confined BX-63 and unconfined LX-04 samples there is a spike in regression rate that drops after $0.2-0.3 \mathrm{~s}$ ). The increase in rate is interpreted to be the onset of ignition and is the result of the creation of physical space in which product species mix and recombine exothermically to produce a luminous flame in a reaction zone with an adequate flame-standoff distance. Following the ignition spike, the burn rates, shown in 
Table 2, stabilize or slightly decrease with time. Accounting for temperature, $\mathrm{T}$, sensitivity on conductive burn rate, $\mathrm{m}$, according to the known relationship [34],

$$
\sigma_{T}=\frac{\partial \ln m}{\lambda_{T}}
$$

suggests that the pre-ignition rates of surface regression that enlarge the ignition volume are too low $\left(\approx 0.08-0.10 \mathrm{~mm} \mathrm{~s}^{-1}\right)$ to be normal burning of solid HMX-based PBXs at $\approx 523 \mathrm{~K}$, therefore we believe this to be pyrolysis. Alternatively, the postignition rates are within the range of published burn rate values [35,36] adjusted with temperature sensitivity coefficients [34], $\sigma \mathrm{T}$,

$(0.002>\sigma \mathrm{T}>0.008 \mathrm{~K}-1)$ at constant ambient pressure.

Accompanying the onset of ignition in the unconfined BX-63 sample, the melt layer becomes thinner, and the filamentous structures (believed to be unreacted residue) evident inside the ignition volume, vanish. The high adiabatic flame temperature of HMX [37] $(\approx 3200 \mathrm{~K})$, and the resulting high thermal gradient between the flame reaction zone and the condensed fuel, would account for both the rapid decomposition and extinction of the filamentous residue in the dark zone, as well as the creation of a thinner melt layer generated by conductive heat transfer from the flame sheet. This is consistent with the widely accepted ambient- pressure structure of stable conductive burning [37].

The significant difference in burn rate between unconfined BX-63, and both confined BX-63 and unconfined LX-04 demands further consideration (Fig. 12). Both BX-63 samples are chemically identical and would be expected to have the same $\sigma \mathrm{T}$. That they do not suggests that the difference might be due to the damage morphology instead, e.g., $\varphi f$, and an associated effect like a gas-mediated convective burn mode. In this case, one would expect the LX-04 to have an similarly enhanced burn rate because of it's similar $\varphi$ f and connected porosity fraction; but this is not the case. The primary radiographically observable difference is the preignition melt layer. However, our data show the burn progresses through the pre-ignition melt layer and continues at the same, or a slightly decreasing, rate through the unwetted medium, thereby eliminating that as a satisfying explanation. We are left to speculate that the burn rate difference is due to existence of porosity combined with surface chemistry of the exposed binder fraction, either causing rate enhancement in BX-63, or rate retardation in LX-04. If the effect is chemical, it would not be confirmable by radiographic observations. Further research will be required to identify a mechanism.

\section{Conclusions}

The application of synchrotron $\mathrm{x}$-ray sources and associated imaging technologies (specifically inline, phase contrast imaging and computed tomography) has been demonstrated to be a powerful tool for the interrogation of key safety issues for these reactive, weakly x-ray absorbing materials. Recent experiments at the Diamond Light Source I13-2 beamline, have produced detailed micro-CT image data and dynamic radiographic sequences characterizing the evolution of porosity in thermallydamaged PBXs. Radiography, resolving the influence of physical structure upon slow cookoff phenomena, has never before been observed at such high spatial resolution. Contained within the datasets are direct observations of the formation and evolution of an internal ignition volume and the role of damage-induced morphology in the transition to bulk ignition and burn propagation. The structure of this ignition volume, generation and transport of a predominately HMX melt layer, and subsequent surface regressive burning, evolves differently depending on the confinement at interfaces, as well as the quantity, nature and connectedness of porosity within the medium. 
This work also shows how surface energy effects between liquid phase HMX and thermally resilient fluoropolymer binder systems, combined with characteristics of the pore field, can eliminate the transport of molten HMX and the development of a pre-ignition melt layer. Current continuum models cannot capture these details and may be omitting important physics.

Ongoing efforts to reconstruct and analyze the 3D pore field characteristics will further improve understanding of the physics controlling thermal degradation, gas and liquid permeation and burn progression at the micro and mesoscale. Specifically, quantitative image analysis has allowed us to measure the amount of porosity and its evolution with exposure duration and temperature for each of the samples. Additionally, future descriptions of flow network topology and its development, will allow for improvements in numerical damage models for PBXs and offer insight to the physical processes of debonding at the crystal-binder interface and multi-phase transport. This work represents the start of a new phase of investigation that will allow us to marry the micromechanics of composite energetic materials, including interactions between the polymer and crystal phases, with the decomposition chemistry of the reactive inclusions. These investigations will deliver physically consistent descriptions to create predictive models that will allow agencies to reduce worrisome threat exposures to explosives and design safer energetic systems for the future.

\section{Declaration of Competing Interest}

The authors declare that they have no known competing financial interests or personal relationships that could have appeared to influence the work reported in this paper.

\section{Acknowledgments}

The authors thank Diamond Light Source for the award of beamtime (proposals MT15068, MT16650 and MT18198) and the staff of the Diamond Manchester beamline I13. We gratefully acknowledge additional funding from our sponsors and colleagues in the DOE Science Programs and the LANL NSR\&D Program. Specifically, thanks to Dana Dattelbaum, Scott Jackson, Tommy Morris, Paul Peterson, Tammy Diaz and Dan Borovina for their continuing support. Bryce Tappan provided helpful discussion and TGA data for binder decomposition; his chemistry expertise and willingness to help is appreciated. Explosive samples packaging and transport was arranged by colleagues at the UK Atomic Weapons Establishment; we thank Peter Bolton, Annette Glauser, Adam Hazelwood, Paul Ryan, Steve James and Steve Goveas for this important contribution. This work was performed under the auspices of the U.S. Department of Energy's National Nuclear Security Administration, at Los Alamos National Laboratory, managed by Triad, LLC. under contract 89233218CNA000001.

\section{Appendix A. Density calculations}

Consider a unit cell at $285^{\circ} \mathrm{C}$ filled with a PBX consisting of these masses; M $\delta$, of solid $\delta$-HMX; Ml, of molten HMX; $\mathrm{Mb}$ of binder, and $\mathrm{Mg}$, of gas in the pore volume. The total density, $\rho$ tot, of this can be written as

$$
\rho_{\text {tot }}=\frac{M_{0}+M_{l}+M_{b}+M_{g}}{V}
$$


where $\mathrm{V}$ is the volume of the unit cell. This can be rewritten as,

$$
\begin{aligned}
\rho_{\text {tot }}= & \frac{M_{\delta}+M_{l}+M_{b}+M_{g}}{V_{b}+V_{l}+V_{b}+V_{g}} \\
= & \frac{M_{\delta}}{V_{\delta}+V_{l}+V_{b}+V_{g}}+\frac{M_{l}}{V_{\delta}+V_{l}+V_{b}+V_{g}} \\
& +\frac{M_{b}}{V_{\delta}+V_{l}+V_{b}+V_{g}}+\frac{M_{g}}{V_{\delta}+V_{l}+V_{b}+V_{g}}
\end{aligned}
$$

where $\mathrm{V} \delta, \mathrm{Vl}, \mathrm{Vb}$ and $\mathrm{Vg}$ are the sub-volumes of the delta HMX, molten HMX, binder, and gas. Next we can multiple each of our terms by unity, ie. $V x / V x$, to get

$$
\begin{aligned}
\rho_{\text {tot }} & =\frac{V_{\delta}}{V_{\delta}+V_{l}+V_{b}+V_{g}} \frac{M_{\delta}}{V_{\delta}}+\frac{V_{l}}{V_{\delta}+V_{l}+V_{b}+V_{g}} \frac{M_{l}}{V_{l}} \\
& +\frac{V_{b}}{V_{\delta}+V_{l}+V_{b}+V_{g}} \frac{M_{b}}{V_{b}}+\frac{V_{g}}{V_{\delta}+V_{l}+V_{b}+V_{g}} \frac{M_{g}}{V_{g}}
\end{aligned}
$$

which clearly the volume fraction times the density of each component. Or,

$$
\rho_{t o t}=\alpha_{\delta} \rho_{\delta}+\alpha_{l} \rho_{l}+\alpha_{b} \rho_{b}+\alpha_{g} \rho_{g}
$$

where $\alpha$ is the volume fraction of the component. We can write the density relation in terms of the mass fraction in a similar manner as,

$$
\frac{1}{\rho_{t o t}}=\frac{\chi_{\delta}}{\rho_{\delta}}+\frac{\chi_{l}}{\rho_{l}}+\frac{\chi_{b}}{\rho_{b}}+\frac{\chi_{g}}{\rho_{l}}
$$

where $\chi$ is the mass fraction.

Now we evaluate the four hypothetical mechanisms, enumerated in Section 4.4, for generating the dense zone observed by radiography in unconfined BX-63. Consider two connected units cells of hot BX-63 connected to a gas reservoir (i.e., the ignition vol ume). These unit cells are assumed to be representative voxels.

Initially, both unit cells contain some identical volume fraction of $\delta$-HMX, binder (we assume it has not decomposed), and some volume fraction of gas (equivalent to final porosity, $\varphi f$ ). The initial volume fraction ratio of HMX:binder is also assumed to be conserved for elevated temperature calculations. At $285{ }^{\circ} \mathrm{C}, \mathrm{HMX}$ will have a density of $1.715 \mathrm{~g} \mathrm{~cm}-3[38]$ due to the $\beta-\delta$ phase transition and thermal expansion, and will occupy a volume fraction $\alpha \delta=0.757$. For liquid HMX, we use a density estimate of $1.651 \mathrm{~g} \mathrm{~cm}-3$ from molecular dynamics simulations by Bedrov et al. 
[39]. The change in volume fraction during melt, $\Delta \alpha$ melt $=(1-\rho 1 / \rho \delta)=0.037$ (a $3.7 \%$ increase). Density of the binder system in BX-63 is calculated with Cheetah 8.0[40] to be $1.486 \mathrm{~g} \mathrm{~cm}-3$, and we assume it will occupy a volume fraction $\alpha b=0.096$. Lastly, if we assume the gas to be $\mathrm{N} 2$ which behaves as an ideal gas at this temperature, we calculate its density to be $6.11 \times 10-4 \mathrm{~g} \mathrm{~cm}-3$. Below the HMX melting point, we apply Eq. A.5, using the $p$ f measured from CT for $\alpha \mathrm{g}$, we can write the initial density in each cell as,

$\rho 0=\alpha \delta \rho \delta+\alpha b \rho b+\alpha g \rho g$

$=0.757(1.715)+0.096(1.486)+0.147(6.11 \times 10-4)$

$=1.441 \mathrm{~g} \mathrm{~cm}-3$.

Hypothesis \#1, Compaction:

All of the porosity gets crushed and eliminated. Applying Eq. A.6, final density, $\rho f$, becomes,

$$
\rho_{f}=\frac{1}{\frac{x_{\delta}}{\rho_{\delta}}+\frac{x_{b}}{\rho_{b}}}=\frac{1}{\frac{0.91}{1.715}+\frac{0.09}{1.486}}=1.692 \mathrm{~g} \mathrm{~cm}^{-3}
$$

This equates to a $17.4 \%$ increase in unit cell density, which should be clearly detectable.

Hypothesis \#2, Convective heating from gas flow, condensed phases stationary: Here we calculate the unit cell density when all of the

$\delta$-HMX melts, expands, and displaces gas from the volume.

$\rho f=(\alpha \delta+\Delta \alpha$ melt $) \rho l+\alpha b \rho b+(\alpha g-\Delta \alpha$ melt $) \rho g$

$=(0.757+0.037) 1.651+0.096(1.486)$

$+(0.147-0.037) 6.11 \times 10-4$

$=1.454 \mathrm{~g} \mathrm{~cm}-3$.

This equates to a $0.9 \%$ increase in unit cell density, which is only marginally detectable.

Hypothesis \#3, melt locus from thermochemical runaway, condensed phases stationary. This produces the same result as for hypothesis \#2.

Hypothesis \#4, melt with liquid HMX transport via wicking mechanism: For this example, we assume melt occurs in the donor cell (superscript D), but not yet in the connected acceptor cell (superscript A). Molten HMX is then wicked, via capillary action from the donor to acceptor, completely filling the porosity in the acceptor and displacing gas further downstream to the next connected cell. The density of the acceptor cell becomes,

$$
\begin{aligned}
& \rho f \mathrm{~A}=\alpha \delta \rho \delta+\alpha \mathrm{b} \rho \mathrm{b}+\alpha \mathrm{g} \rho \mathrm{l} \\
& =0.757(1.715)+0.096(1.486)+0.147(1.651) \\
& =1.684 \mathrm{~g} \mathrm{~cm}
\end{aligned}
$$

This equates to a $16.9 \%$ increase in unit cell density, which should be clearly detectable. 
And the donor cell then becomes,

$$
\begin{aligned}
\rho_{f}^{D} & =\left(\alpha_{\delta}+\Delta \alpha_{\text {melt }}\right) \rho_{l}+\alpha_{b} \rho_{b}-\alpha_{g} \rho_{l} \\
& =(0.757+0.037) 1.651+0.096(1.486)-0.147(1.651)=1.211 \mathrm{~g} \mathrm{~cm}^{-3}
\end{aligned}
$$

This equates to a $16.0 \%$ decrease in unit cell density, which should be clearly detectable.

\section{Supplementary material}

Supplementary material associated with this article can be found, in the online version, at doi:10.1016/j.combustflame.2020.12. 025.

\section{References}

[1] B. Asay, Introduction, in: B. Asay (Ed.), Non-shock Initiation of Explosives, Shock Wave Science and Technology Reference Library, 5, Springer, Berlin Heidelberg, DE (2010), pp. 1-14.

[2] R. Mainiero, J. Rowland, A review of recent accidents involving explosives transport, Accid. Invest. Q. (56) (2009) 22-25.

[3] M. Baer, Modeling heterogeneous energetic materials at the mesoscale, Thermochim. Acta 384 (2002) 351-367.

[4] W.L. Perry, B. Clements, X. Ma, J. Mang, Relating microstructure, temperature, and chemistry to explosive ignition and shock sensitivity, Combust. Flame 190 (2018) 171-176.

[5] Y. Liu, Z. Duan, Z. Zhang, Z. Ou, F. Huang, A mesoscopic reaction rate model for shock initiation of multi-component PBX explosives, J. Hazard. Mater. 317 (2016) 44-51.

[6] S. Jackson, Deflagration phenomena in energetic materials: An overview, in: B. Asay (Ed.), Non-Shock Initiation of Explosives, Shock Wave Science and Technology Reference Library, 5, Springer (2010), pp. 245-292.

[7] N. Bourne, J. Field, Bubble collapse and the initiation of explosion, Proc. R. Soc. Lond. A 435 (1991) 423-435.

[8] N. Bourne, A. Milne, The temperature of a shock-collapsed cavity, Proc. R. Soc. Lond. A (459) (2003) 1851-1861.

[9] G. Parker, E. Heatwole, M. Holmes, B. Asay, P. Dickson, J. McAfee, Deflagration-to-detonation transition in hot HMX and HMX-based polymer-bonded explosives, Combust. Flame 15 (2020) 295308.

[10] P.D. Peterson, J.T. Mang, B.W. Asay, Quantitative analysis of damage in anoctahydro1,3,5,7-tetranitro-1,3,5,7-tetrazonic-based composite explosive subjected to a linear thermal gradient, J. Appl. Phys. 97 (2005) 093507.

[11] G.R. Parker, P.D. Peterson, B.W. Asay, P.M. Dickson, W.L. Perry, B.F. Henson, L. Smilowitz, M.R. Oldenborg, Examination of morphological changes that affect gas permeation through thermally damaged explosives, Propellants Explos. Pyrotech. 29 (2004) 274-281. 
[12] A. Renlund, J. Miller, W. Trott, K. Erickson, M. Hobbs, R. Schmitt, G. Wellman, M. Baer, Characterization of thermally degraded energetic materials, in: J. Short, J. Kennedy (Eds.), Eleventh International Detonation Symposium, Office of Naval Research, Arlington, VA, USA (1998), pp. 127-134. ONR 33300-5

[13] T.M. Willey, L. Lauderbach, F. Gagliardi, T. van Buuren, E. Glascoe, J. Tringe,

J.R.I. Lee, H. Springer, J. Ilavsky, Mesoscale evolution of voids and microstructural changes in HMX-based explosives during heating through the $\beta-\delta$ phase transition, J. Appl. Phys. 118 (2015) 055901.

[14] G. Parker, B.W. Asay, P.M. Dickson, P. Rae, A. Ionita, Non-random crack opening in partiallyconfined, thermally damaged PBX 9501 and observations on its effects on combustion, in: M. Elert, M. Furnish, R. Chau, N. Holmes, J. Nguyen (Eds.), Shock Compression of Condensed Matter, CP955, American Insititute of Physics, Melville, NY, USA (2007), pp. 853-856.

[15] B.W. Asay, G. Parker, P.M. Dickson, B.F. Henson, L. Smilowitz, Dynamic measurement of the permeability of an explosive undergoing thermal damage, J. Energetic Mater. 21 (2004) 25-39.

[16] G.R. Parker, B.W. Asay, P.M. Dickson, B.F. Henson, L.B. Smilowitz, Effect of thermal damage on the permeability of PBX 9501, in: M. Furnish, Y. Gupta, J. Forbes (Eds.), Shock Compression of Condensed Matter, CP703, American Insititute of Physics, Melville, NY, USA (2003), pp. 1009-1012.

[17] G.R. Parker, P.M. Dickson, B.W. Asay, L.B. Smilowitz, B.F. Henson, W.L. Perry, Understanding the mechanisms leading to gas permeation in thermally damaged PBX 9501, in: M. Furnish, M. Elert, T. Russell, C. White (Eds.), Shock Compression of Condensed Matter, CP845, American Insititute of Physics, Melville, NY, USA (2005), pp. 1101-1104.

[18] J.T. Mang, C.B. Skidmore, R.P. Hjelm, P.M. Howe, Application of small-angle neutron scattering to the study of porosity in energetic materials, J. Mater. Res. 15 (2000) 1199-1208.

[19] T.M. Willey, T. van Buuren, J.R.I. Lee, G.E. Overturf, J.H. Kinney, J. Handly, B.L. Weeks, J. Ilavsky, Changes in pore size distribution upon thermal cycling of TATB-based explosives measured by ultra-small angle x-ray scattering, Propellants Explos. Pyrotech. 31 (2006) 466471.

[20] P.C. Hsu, M. DeHaven, M. McClelland, L. Maienschein, Thermal damage on LX-04 mock material and gas permeability assessment, Propellants Explos. Pyrotech. 31 (2006) 56-60.

[21] C. Skidmore, D. Phillips, N. Crane, Microscopical examination of plastic-bonded explosives, Microscope 45 (1997) 127-136.

[22] C. Skidmore, D. Phillips, P.M. Howe, J.T. Mang, J.A. Romero, The evolution of microstructural changes in pressed HMX explosives, in: J. Short, J. Kennedy (Eds.), Eleventh International Detonation Symposium, Office of Naval Research, Arlington, VA, USA (1998), pp. 556-564.

[23] M. Herrmann, W. Engel, N. Eisenreich, Thermal expansion, transitions, sensitivities and burning rates of HMX, Propellants Explos. Pyrotech. 17 (1992) 190-195.

[24] L. Smilowitz, B.F. Henson, D.M. Oschwald, N. Suvorova, D. Remelius, Internal sub-sonic burning during an explosion viewed via dynamic x-ray radiography, Appl. Phys. Lett. 111 (2017) 184103.

[25] L. Smilowitz, B.F. Henson, J. Romero, B.W. Asay, C. Schwartz, A. Saunders, F. Merrill, C. Morris, K. Kwiatkowski, G. Hogan, P. Nedrow, M. Murray, T. Thompson, W. 
McNeil, P. Rightley, M. Marr-Lyon, Direct observation of the phenomenology of a solid thermal explosion using time-resolved proton radiography, Phys. Rev. Lett. 100 (2008) 228301.

[26] L. Smilowitz, B.F. Henson, J. Romero, B.W. Asay, A. Saunders, F. Merrill, C. Morris, K. Kwiatkowski, G. Grim, F. Mariam, C. Schwartz, G. Hogan, P. Nedrow, M. Murray, T. Thompson, C. Espinoza, D. Lewis, J. Bainbridge, W. McNeil, M. Marr-Lyon, The evolution of solid density within a thermal explosion. I. Proton radiography of pre-ignition expansion, material motion, and chemical decomposition, J Appl Phys 111 (2012) 103515.

[27] L. Smilowitz, B.F. Henson, J. Romero, D.M. Oschwald, Thermal decomposition of energetic materials viewed via dynamic x-ray radiography, Appl. Phys. Lett. 104 (2014) 024107.

[28] L. Smilowitz, B.F. Henson, J. Romero, B.W. Asay, A. Saunders, F. Merrill, C. Morris, K. Kwiatkowski, G. Grim, F. Mariam, C. Schwartz, G. Hogan, P. Nedrow, M. Murray, T. Thompson, C. Espinoza, D. Lewis, J. Bainbridge, W. McNeil, M. Marr-Lyon, The evolution of solid density within a thermal explosion. II. dynamic proton radiography of cracking and solid consumption by bunring, J. Appl. Phys. 111 (2012) 103516.

[29] J. Tringe, J. Kercher, H. Springer, E. Glascoe, H. Levie, P. Hsu, T.M. Willey, J. Molitoris, Numerical and experimental study of thermal explosions in LX-10 and PBX 9501: influence of thermal damage on deflagration processes, J. Appl. Phys. 114 (2013) 043504.

[30] C. Rau, U. Wagner, Z. Pesic, A. De Fanis, Coherent imaging at the diamond beamline I13, Physica Status Solidi A 208 (2011) 2522-2525.

[31] P. Cloetens, M. Pateyron-Salome, J. Buffiere, G. Peix, J. Baruchel, F. Peyrin, M. Schlenker, Observation of microstructure and damage in materials by phase sensitive radiography and tomography, J. Appl. Phys. 81 (1997) 5878.

[32] R.C. Atwood, A. Bodey, S.W.T. Price, M. Basham, M. Drakopoulos, A high-throughput system for high-quality tomographic reconstruction of large datasets at diamond light source, Philos. Trans. R. Soc. A 373 (2015) 20140398.

[33] P. Hsu, M. DeHaven, M. McClelland, S. Chidester, J.L. Maienschein, Characterization of damaged materials, Proceedings of the Thirteeth International Detonation Symposium, Office of Naval Research, Arlington, VA, USA (2006), p. 617. ONR 351-07-01

[34] N. Kubota, Survey of rocket propellants and their combustion characterisitics, Am. Inst. Aeronaut. Astronaut., pp. 1-52.

[35] S.F. Son, H.L. Berghout, C.A. Bolme, D.E. Chavez, D. Naud, M.A. Hiskey, Burn rate measurements of HMX, TATB, DHT, DAAF, and BTATz, Proc. Combust. Inst. 28 (2000) 919-924.

[36] J. Maienschein, J. Koerner, EDC-37 Deflagration Rates at Elevated Pressures, Technical Report, Lawrence Livermore National Laboratory, 2008. LLNL-TR-400989

[37] M. Beckstead, Solid propellant combustion mechanisms and flame structure, Pure Appl. Chem. 65 (1993) 297-307.

[38] C. Xue, J. Sun, B. Kang, Y. Liu, X. Liu, The $\beta$ - $\delta$-phase transition and thermal expansion of octahydro-1,3,5,7-tetranitro-1,3,5,7-tetrazocine, Propellants Explos. Pyrotech. 35 (2010) 333-338.

[39] D. Bedrov, G. Smith, T. Sewell, Temperature-dependent shear viscosity coefficient of octahydro-1,3,5,7-tetranitro-1,3,5,7 (HMX): a molecular dynamics dynamics simulation study, J. Chem. Phys. 112 (2000). 
Parker, Eastwood, Storm et al, Combustion and Flame (2021)

[40] S. Bastea, L. Fried, K. Glaeseman, W. Howard, I. Kuo, P. Souers, P. Vitello, Cheetah 8.0, LLNL-CODE-677327 (2015). 


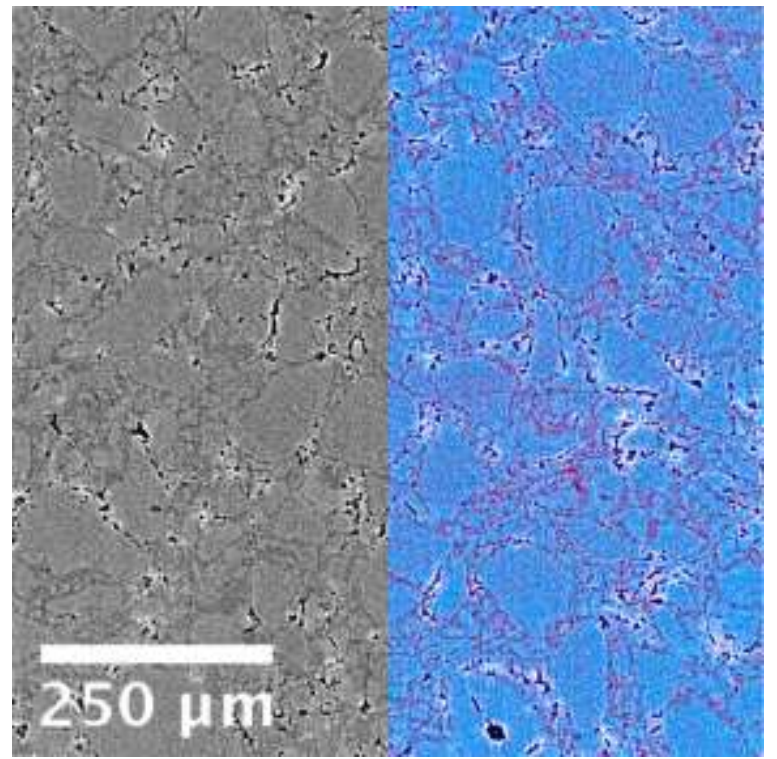

Fig. 1. Phase-contrast CT slice of pristine BX-63 with partial false-color overlay. HMX crystallites (blue), voids (black), binder-rich regions (red), and phase contrast artifacts on high-contrast boundaries (white). (For interpretation of the references to colour in this figure legend, the reader is referred to the web version of this article.) 


\section{Table 1}

PBX formulation details, as pressed.

\begin{tabular}{lll}
\hline Component & LX-04 & BX-63 \\
\hline $\begin{array}{l}\text { HMX mass } \\
\text { fraction (\%) }\end{array}$ & 85 & 91 \\
$\begin{array}{l}\text { Binder mass } \\
\text { fraction (\%) }\end{array}$ & $15^{\mathrm{a}}$ & $9 \mathrm{~b}$ \\
& & \\
$\begin{array}{l}\text { HMX volume } \\
\text { fraction (\%) }\end{array}$ & 82.0 & 86.3 \\
$\begin{array}{l}\text { Binder volume } \\
\text { fraction (\%) }\end{array}$ & 15.4 & 11.0 \\
$\begin{array}{l}\text { Pore volume fraction } \\
\text { (\%) }\end{array}$ & 2.6 & 2.7 \\
$\begin{array}{l}\text { Initial density (g } \\
\text { cm }{ }^{-3} \text { ) }\end{array}$ & 1.843 & 1.812 \\
\hline
\end{tabular}

a LX-04 binder composition: 100 wt-\% Viton A.

b BX-63 binder composition: $\approx 11.1 \mathrm{wt}-\%$ nitrocellulose, $\approx 59.3 \mathrm{wt}-\%$ di-nitro ethylbenzene, $\approx 29.6$ wt-\% tri-nitro ethylbenzene. 


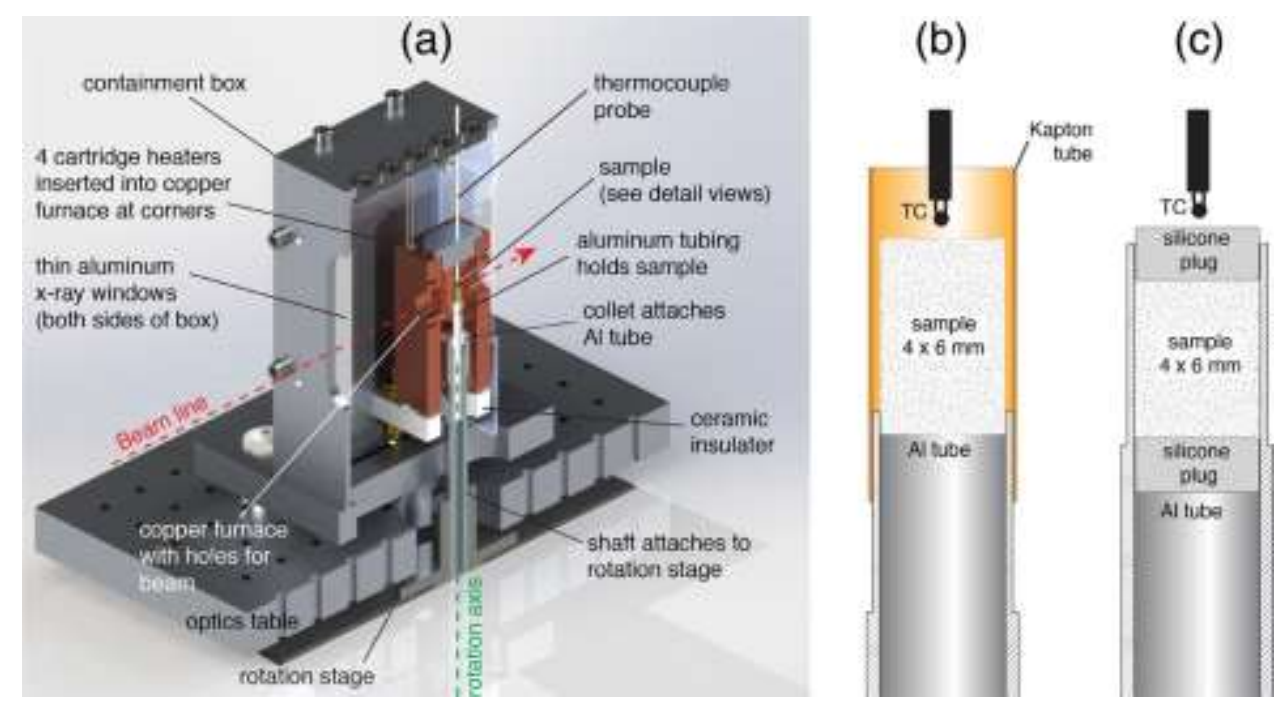

Fig. 2. (a) The furnace assembly fitted around the rotation pedestal, (b) detail of sample in the unconfined configuration, note: the Kapton does not contact the sample, and (c) detail of confined configuration. 


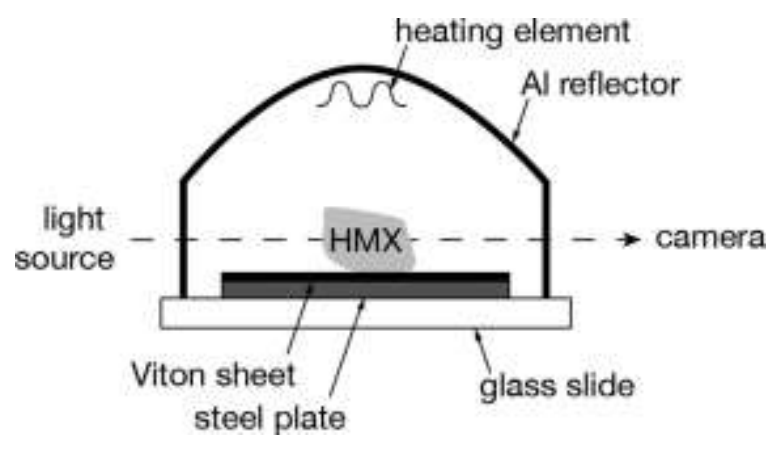

Fig. 3. Illustration of the furnace used for contact angle measurement. 

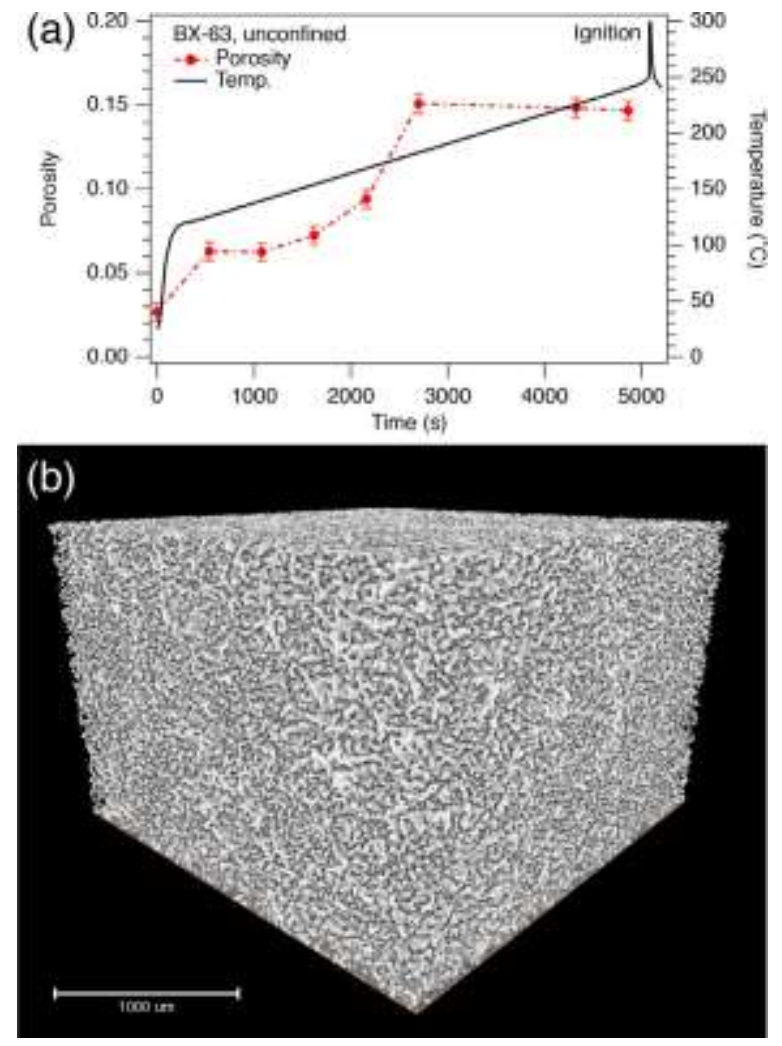

Fig. 4. a) Measured porosity in unconfined BX-63 over time with exposure to the thermal trajectory shown. b) The final CT reconstruction showing only the final porosity, $\varphi f$, (gray) for unconfined BX-63. See the animation in Supplementary Data $\mathrm{S} 1$ for the complete image series. 

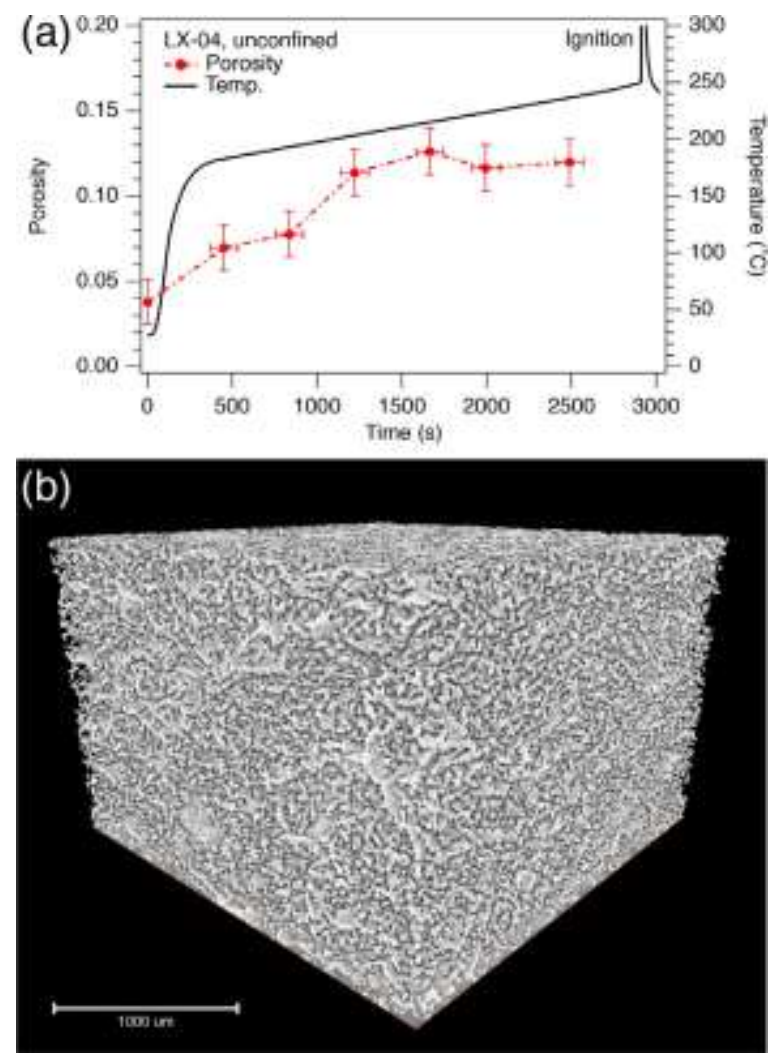

Fig. 5. a) Measured porosity in unconfined LX-04 over time with exposure to the porosity, $\varphi f$, gray) for unconfined L X-04. Black represents non-pore volume. See the animation in Supplementary Data S1 for the complete image series. 

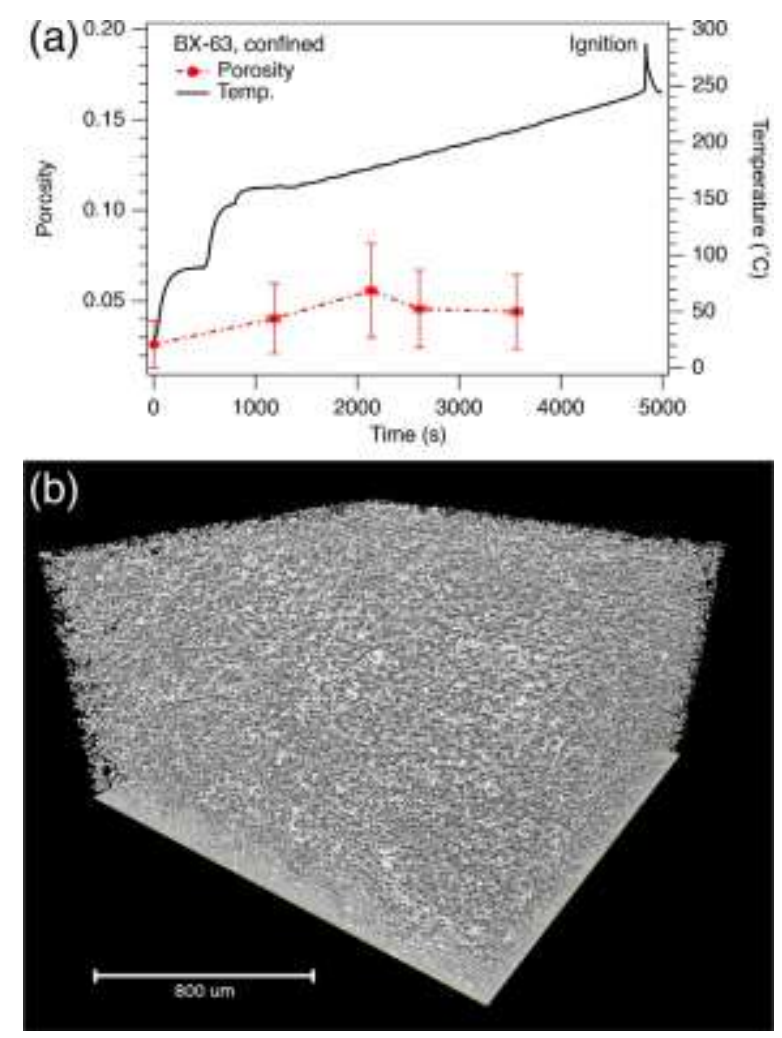

Fig. 6. a) Measured porosity in confined BX-63 over time with exposure to the thermal trajectory shown. b) The final CT reconstruction showing only the final porosity, $\varphi f$, (gray) for confined BX-63. Black represents non-pore volume. See the animation in Supplementary Data $\mathrm{S} 1$ for the complete image series. 


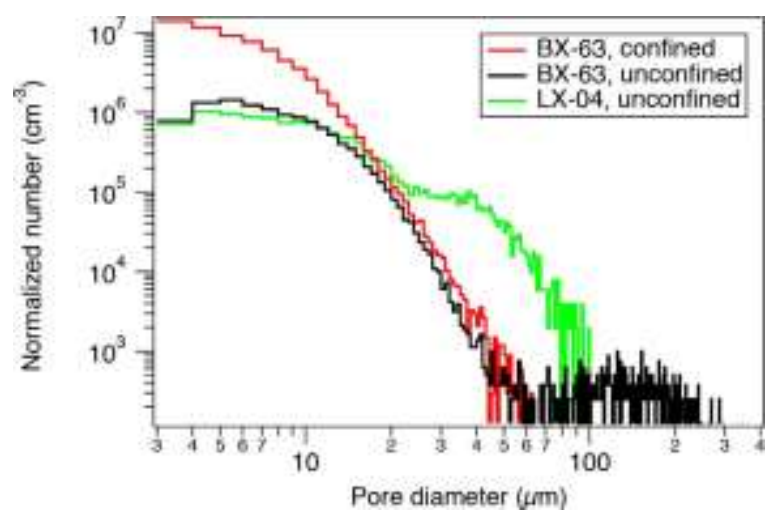

Fig. 7. Normalized size distribution of pore body diameters from the final CT reconstructions for each sample. 


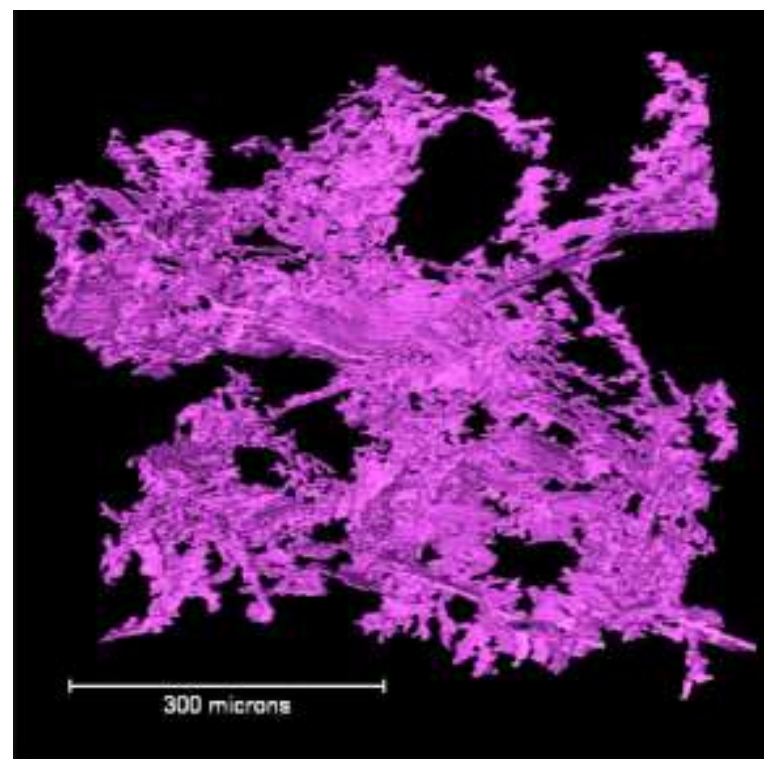

Fig. 8. A subvolume displaying a connected network of porosity (purple) from a 3D CT reconstruction of hot, thermally damaged PBX. The porosity exists surrounding crystallites; this characteristic, which is the result of mechanical debonding at HMXbinder interfaces, is more evident when the feature is rotated as is shown in the Supplementary Data S3 electronic media. (For interpretation of the references to colour in this figure legend, the reader is referred to the web version of this article.) 


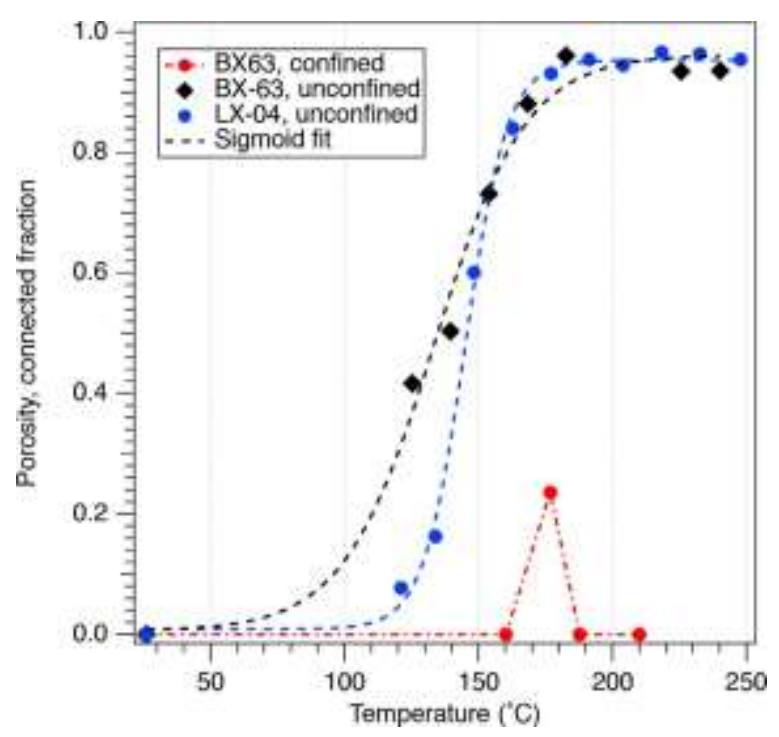

Fig. 9. The fraction of porosity that is connected as a function of temperature. 

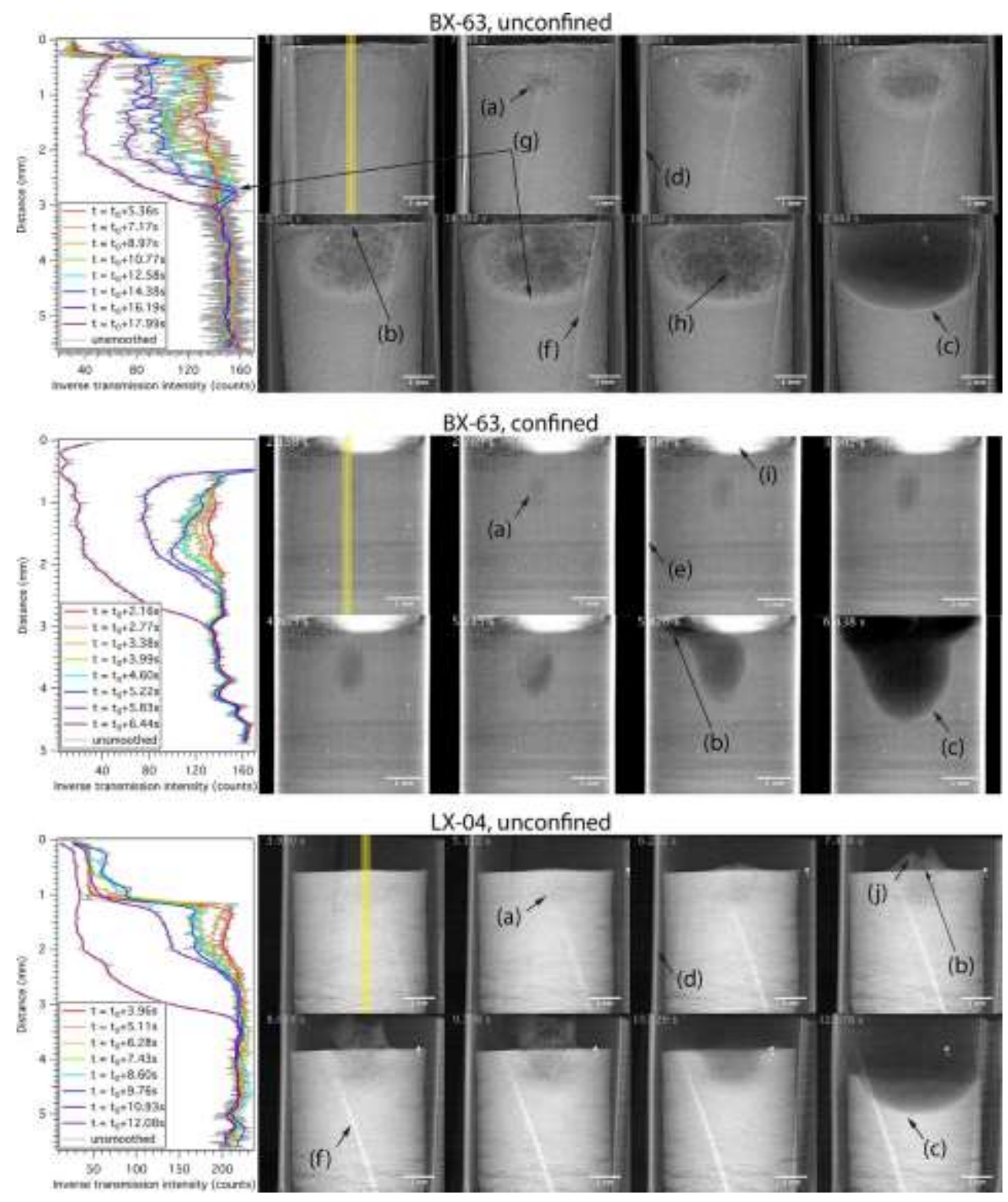

Fig. 10. Average inverse transmission intensity profiles (left column) along the yellow region at time steps corresponding to the sparse frame sequence from a set of radiographs of $\mathrm{HMX}$-based $\mathrm{PBX}$ during cookoff (right). a) Emergence of the ignition volume, b) ignition volume breakout, c) post-ignition melt layer, d) wall of Kapton tube, e) wall of $\mathrm{Al}$ tube, $\mathrm{f}$ ) artifact from wrinkle in Kapton tube, g) pre-ignition melt layer, h) residue, i) silicone plug, and $\mathrm{j}$ ) bulging and fracture of PBX from pressure inside the ignition volume. Ignition onset is shown in the last frame. See also the Supplementary Data S2 electronic media for full sequences of unconfined BX-63 and LX-04. (For interpretation of the references to colour in this figure legend, the reader is referred to the web version of this article.) 


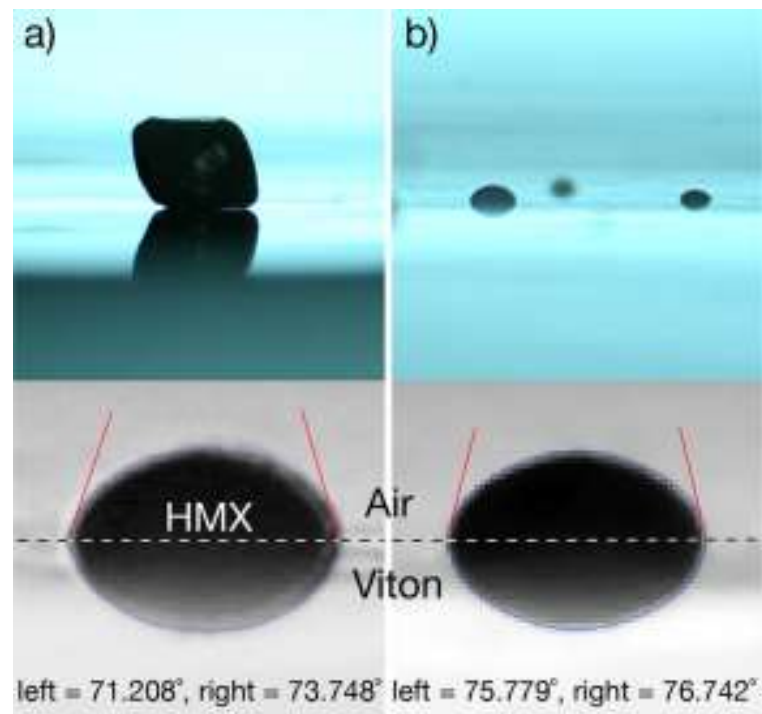

Fig. 11. a) HMX crystal before heating. b) Representative sessile droplets of molten HMX expelled during boiling and used for static contact angle measurement. Example of measurements (bottom, left and right) of each droplet analyzed using the DropSnake plugin in ImageJ. 


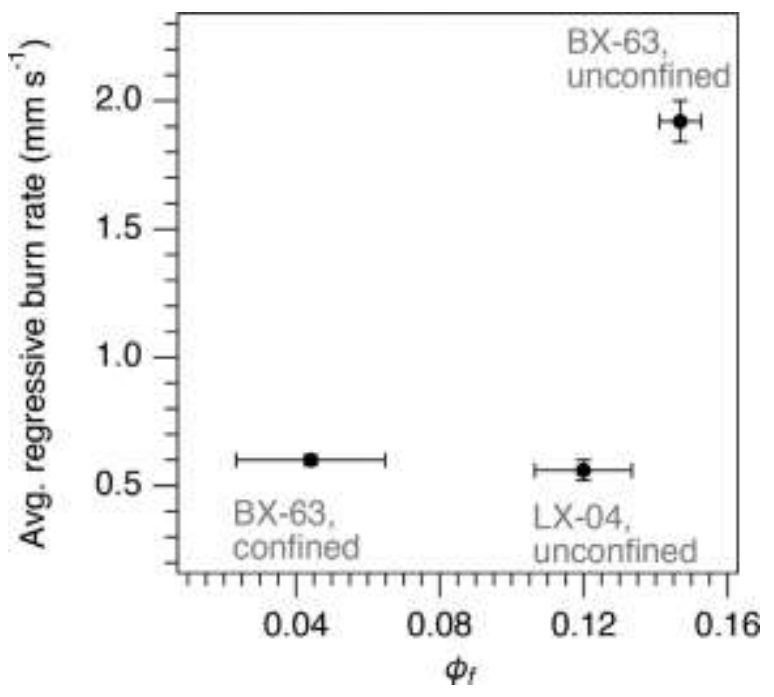

Fig. 12. Regressive burn rate as a function of measured final porosity, $\varphi f$. 
(a)

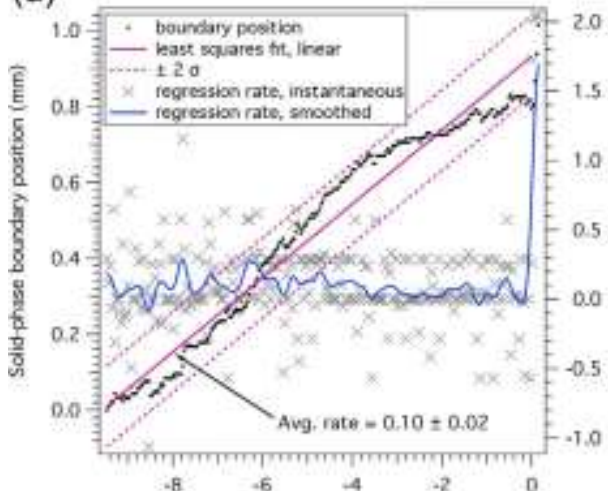

(c)

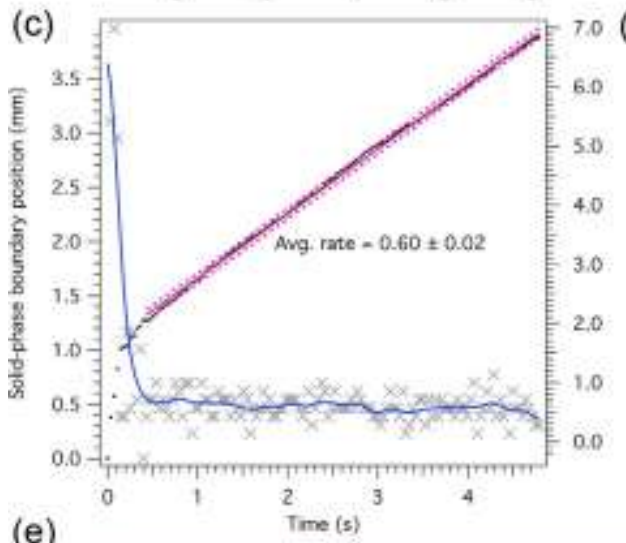

(b)

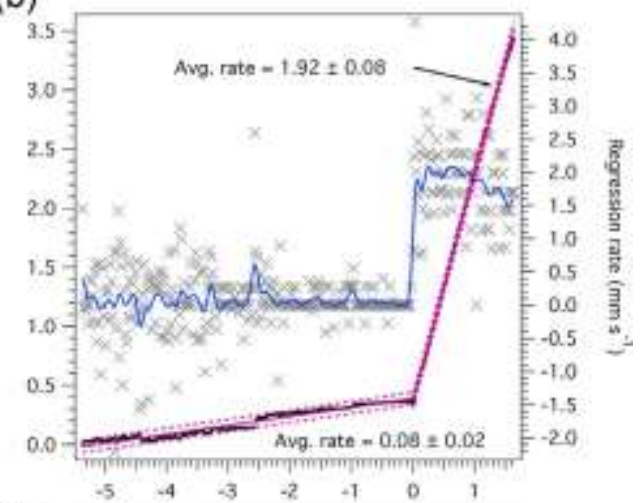

(d)

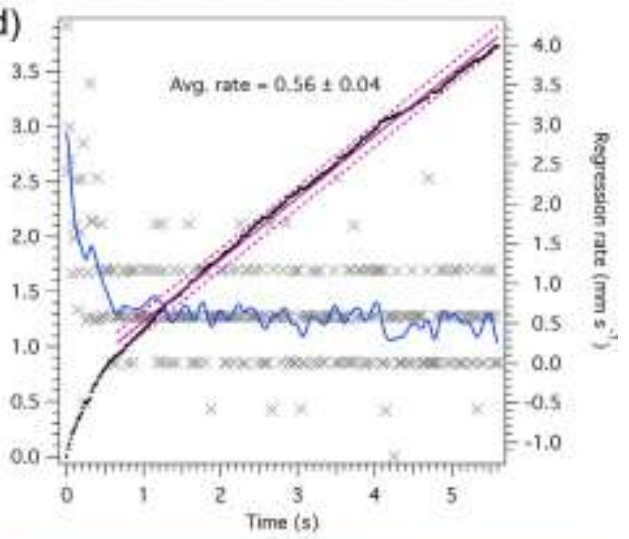

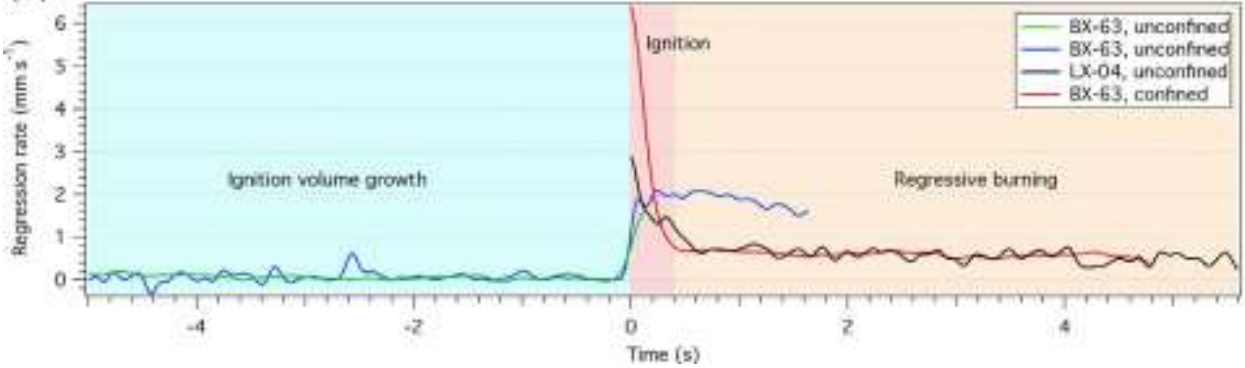

Fig. 13. Surface regression positions and average rates. a), b) Unconfined BX-63, c) confined BX-63, d) unconfined LX-04, and e) regression rate overlay synchronized to the onset of ignition at $\mathrm{t}=0$. 
Parker, Eastwood, Storm et al, Combustion and Flame (2021)

\section{Table 2}

Burn rates for various HMX-based PBXs.

\begin{tabular}{|c|c|c|c|}
\hline PBX type & $\begin{array}{l}\mathrm{m} @ 25^{\circ} \mathrm{C}, \\
1 \mathrm{~atm}\left(\mathrm{~mm} \mathrm{~s}^{-1}\right)\end{array}$ & $\begin{array}{l}\mathrm{m} @ 250^{\circ} \mathrm{C} \\
1 \mathrm{~atm}\left(\mathrm{~mm} \mathrm{~s}^{-1}\right)\end{array}$ & $\begin{array}{l}\sigma_{T} \\
\left(\mathrm{~K}^{-1}\right)\end{array}$ \\
\hline PBX 9501 & $0.3[35]$ & NA & NA \\
\hline LX-04 & $0.2[36]$ & $0.56 \pm 0.04 \dagger$ & 0.005 \\
\hline $\begin{array}{l}\text { BX-63 } \\
\text { (confined) }\end{array}$ & 0.3 [36] & $0.60 \pm 0.02 \top$ & U.UU3 \\
\hline $\begin{array}{l}\text { BX-63 } \\
\text { (unconfined) }\end{array}$ & $0.3[36]$ & $1.92 \pm 0.08^{\dagger}$ & 0.008 \\
\hline
\end{tabular}

